\title{
Incident Invasive Breast Cancer, Geographic Location of Residence, and Reported Average Time Spent Outside
}

\author{
Amy E. Millen, ${ }^{1}$ Mary Pettinger, ${ }^{2}$ Jo L. Freudenheim, ${ }^{1}$ Robert D. Langer, ${ }^{3}$ \\ Carol A. Rosenberg, ${ }^{4}$ Yasmin Mossavar-Rahmani, ${ }^{5}$ Christine M. Duffy, ${ }^{6}$ \\ Dorothy S. Lane, ${ }^{7}$ Anne McTiernan, ${ }^{8}$ Lewis H. Kuller, ${ }^{9}$ \\ Ana Maria Lopez, ${ }^{10}$ and Jean Wactawski-Wende ${ }^{1}$ \\ ${ }^{1}$ Department of Social and Preventive Medicine, School of Public Health and Health Professions, University at Buffalo, \\ Buffalo, New York; ${ }^{2}$ Division of Public Health Sciences, Fred Hutchinson Cancer Research Center, Seattle, Washington; \\ ${ }^{3}$ Outcomes Research Institute, Center for Health Research, Geisinger Health System, Danville, Pennsylvania; \\ ${ }^{4}$ Department of Medicine, Evanston Northwestern Healthcare, Evanston Illinois; ${ }^{5}$ Division of Behavioral \& \\ Nutritional Research, Department of Epidemiology and Population Health, Albert Einstein College of Medicine, \\ Bronx, New York; 'Division of General Internal Medicine, Brown University School of Medicine, Providence, \\ Rhode Island; 'Department of Preventive Medicine, Stony Brook University School of Medicine, Stony Brook, \\ New York; ${ }^{8}$ Prevention Center, Fred Hutchinson Cancer Research Center, Seattle, Washington; ${ }^{9}$ Department of \\ Epidemiology, University of Pittsburgh, Pittsburgh, Pennsylvania; and ${ }^{10} \mathrm{Clinical}$ Medicine and Pathology, \\ Arizona Telemedicine Program, Arizona Cancer Center, University of Arizona, Tucson, Arizona
}

\begin{abstract}
There have been reports of greater breast cancer incidence and mortality at northern compared with southern latitudes postulated to be related to vitamin D exposure. Among 71,662 participants in the Women's Health Initiative Observational Study (WHIOS) free of cancer at baseline (1993-1998), associations were explored between incident invasive postmenopausal breast cancer $(n=2,535)$, over $\sim 8.6$ years follow-up, and the following: $(a)$ region of residence at birth, age 15 years, age 35 years; $(b)$ region of residence at WHIOS baseline; and $(c)$ clinic center solar irradiance. Hazard ratios and $95 \%$ confidence intervals (CI) for breast cancer were estimated after adjustment for individual level confounders. There was no difference in breast cancer risk by region of earlier life, baseline residence, or solar irradiance measured in Langelys (gm-cal) per
\end{abstract}

$\mathrm{cm}^{2}$. There was an observed $15 \%$ decreased risk among women residing in areas of low versus high solar irradiance measured in Watts per $\mathrm{m}^{2}$ (95\% CI, 2-26\%). However, the associated $\boldsymbol{P}_{\text {trend }}$ of 0.20 was not significant. Conversely, women who reported spending on average $<30$ minutes versus $>2$ hours outside in daylight year round at WHIOS year 4 follow-up $(n=46,926)$, had a $20 \%\left(95 \% \mathrm{CI}, 2-41 \% ; P_{\text {trend }}=0.001\right)$ increased risk of breast cancer. In conclusion, region of residence and geographic solar irradiance are not consistently related to risk of breast cancer and may not be sufficient proxy measures for sunlight/vitamin $D$ exposure. The observed association between time spent outside and breast cancer risk support the hypothesis that vitamin $D$ may protect against breast cancer. (Cancer Epidemiol Biomarkers Prev 2009;18(2):495-507)

\section{Introduction}

Breast cancer mortality and incidence rates have been found to be higher among U.S. postmenopausal women living at northern compared with those living in southern latitudes (1-3) and inversely associated in U.S. women with increasing levels of total average sunlight energy striking the ground (4-6). Similar results have also been observed in other countries $(7,8)$. It has been suggested that the association between breast cancer and geographic variation may be explained, at least in part, by exposure to vitamin $\mathrm{D}(4,8)$. Lower latitude means greater potential for sunlight exposure and thus synthesis of vitamin D. Humans can synthesize vitamin D from a cholesterol precursor in the skin; the majority of circulating vitamin D in most people is obtained through

Received 7/18/08; revised 10/23/08; accepted 11/25/08; published OnlineFirst 02/03/2009 Requests for reprints: Amy E. Millen, Department of Social and Preventive Medicine, School of Public Health and Health Professions, University at Buffalo, 270 Farber Hall Buffalo, NY 14214-8001. Phone: 716-829-5377; Fax: 716-829-2979. E-mail: aemillen@buffalo.edu

Copyright (C) 2009 American Association for Cancer Research doi:10.1158/1055-9965.EPI-08-0652 sunlight exposure (reviewed in ref. 9), less from diet and supplements. However, diet and supplements may contribute more significantly in Northern climates.

Interest in vitamin $\mathrm{D}$ as a protective agent against cancer came from research showing that the active form of vitamin $\mathrm{D}, 1,25$ dihydroxyvitamin $\mathrm{D}$, has an antiproliferative effect on cultured human cancer cells $(10,11)$. Research in humans and in animals supports a potential role for vitamin $\mathrm{D}$ in breast cancer prevention, as previously reviewed $(12,13)$.

However, few studies that have investigated relationships between region of residence and breast cancer risk have used incidence data $(6,8,14,15)$. Most previous studies focused on mortality from breast cancer $(1-5,7,16$, $17)$, and were often assessed at the population level $(1,4,5$, $7,17)$; adjusted for risk factors assessed at the regional, not individual level $(1,2,4-8,16,17)$; and were unable, or did not, explore associations by race or ethnicity. Furthermore, there has been little exploration of differences in effect of exposures at different periods of life. Migration of individuals could affect our understanding of the effect of sunlight exposure on risk. 
Using data from the Women's Health Initiative Observational Study (WHIOS), we investigated associations between incident invasive breast cancer among postmenopausal women and residential estimates of vitamin D exposure: $(a)$ region of residence at earlier life periods (birth, age 15 years, age 35 years); (b) region of residence at baseline WHIOS enrollment (1993-1998); and (c) clinic center solar irradiance. In addition, a measure of average time reported spent outside, as a proxy measure for sunlight exposure, was also available for analysis. This large prospective multiethnic cohort provides a unique opportunity to study associations between incident breast cancer and geographic variation.

\section{Materials and Methods}

The WHIOS. The WHIOS is a multicenter study focused on the major causes of morbidity and mortality of postmenopausal (50-79 y) women over the course of 8 to 12 y $(18,19)$. Between October 1993 and December $1998,93,676$ women were enrolled in the WHIOS from 40 clinic centers across the United States, including $\sim 17 \%$ as minority women (20). The Institutional Review Boards at each participating institution approved all protocols and consent forms. All women gave signed informed consent.

Ascertainment of Breast Cancer Outcomes. Over an average $8.6 \mathrm{y}$ of follow-up, from baseline to August 18, 2006, breast cancer cases were identified mainly via annual follow-up questionnaires (21). Reported breast cancers were verified by ascertainment of medical records (21). Study physicians adjudicated events using standardized criteria (21). Breast cancer was coded according to National Cancer Institute Surveillance, Epidemiology, End Results guidelines (22). Detailed characteristics of the cancer were coded [i.e., date of diagnosis, the extent of disease, tumor morphology, and estrogen (ER) and progesterone receptor (PR) status]. Follow-up time for each woman was accrued from enrollment to the date of diagnosis of breast cancer, death from a nonbreast cancer cause, loss to follow-up, or last contact.

Sample Selection. Women were excluded from the starting sample of 93,676 participants if they reported at baseline any previous history of cancer $(n=11,948)$, other than nonmelanoma skin cancer, or were missing data with respect to their previous history of breast cancer $(n=875)$. Women were further excluded if they were missing dietary data $(n=3,189)$ and information on the following risk factors: education $(n=660)$, family history of breast cancer $(n=775)$, age at menarche $(n=$ $206)$, age at menopause $(n=3,178)$, parity $(n=414)$, age at first birth $(n=162)$, and physical activity $(n=794$; numbers not mutually exclusive). There were originally 7,800 women with missing data on age at first birth. They were assigned the most common age at first birth among women with the same number of children when possible. After all exclusions, the study sample consisted of 71,662 women with 2,535 (3.5\%) having incident invasive breast cancer diagnosed during prospective follow-up.

Data Collection. At WHIOS baseline, women provided self-reported data via questionnaires on demograph- ics, risk exposure, and family and medical history (20). After enrollment, participants completed annual mailed self-administered questionnaires to update life-style and medical information $(18,20)$. At year 3 , most participants attended a clinic visit at which the annual questionnaire was collected; forms were mailed to those who did not attend this visit.

Dietary and Supplement Data. At baseline, participants completed a self-administered, modified Block Food Frequency Questionnaire $(23,24)$ to assess usual dietary intake over the previous 3 mo. This Food Frequency Questionnaire has been previously validated in other populations $(25,26)$. The Food Frequency Questionnaire was processed using a nutrient database designed by the Minnesota Nutrient Data System to obtain participant nutrient and food intake information. Information on intake of nutrients from supplements (such as vitamin D) was collected in-person at WHIOS baseline. A standardized interviewer-administered form was used to collect information on the dose, frequency, and duration of current supplement use $(27,28)$.

Region of Residence. Participants reported the state in which they resided at birth, at ages 15 and 35 y on selfadministered questionnaires. Four categories for region of residence were created at these ages defined by latitude (29): outside the United States, Southern (states with northern borders $\leq 37^{\circ} \mathrm{N}$ ), Northern (states with southern borders $>40^{\circ} \mathrm{N}$ ), and Middle (states that did not categorize as Southern or Northern). Data on women born or residing outside of the United States at these ages could not be further classified by latitude, as no additional information was provided for these women on residence at these time points. Participants were also assigned a region of residence at baseline corresponding to their WHIOS clinic center latitude and categorized as Southern $\left(\leq 37^{\circ} \mathrm{N}\right)$, Middle $\left(>37^{\circ} \mathrm{N}\right.$ to $\left.40^{\circ} \mathrm{N}\right)$, and Northern $\left(>40^{\circ} \mathrm{N}\right)$.

The latitude of $37^{\circ} \mathrm{N}$ was chosen as a cut point because previous data have shown that greater rates of cancer incidence are observed above $37^{\circ} \mathrm{N}$ (reviewed in ref. 30) and because less UVB photons reach the earth above $37^{\circ} \mathrm{N}$ from November through February (9).

Solar Irradiance. Vitamin D is synthesized in the skin from a cholesterol precursor when skin is exposed to UVB radiation, of which the wavelengths ranges from 290 to $315 \mathrm{~nm}$ (31). Only the solar irradiance measure of UVB is specific to this wavelength range.

Solar irradiance values were estimated for each of the 40 Women's Health Initiative clinic centers in measures of Langleys (gm-cal) per $\mathrm{cm}^{2}$ and Watts $(\mathrm{J} / \mathrm{s})$ per $\mathrm{m}^{2}$. Annual mean Langleys were obtained from measurements made by the US Weather Bureau and adapted for use in Women's Health Initiative from a previous publication (32). The Langleys values are estimates of the mean annual total solar radiation reaching the ground and are an "estimate of the amount of sunlight due to gross geographic and meteorologic factors over large areas" (32). Total solar irradiance is a measure of all wavelengths emitted by the sun.

A second measure of solar irradiance, in Watts, was determined from NASA's Total Ozone Mapping Spectrometer and Earth Radiation Budget Experiment data for the year 1989 (33). The Watts values measure 
the daily UVB flux reaching the earth, within the wavelength range necessary to synthesize vitamin D (290-315 nm), and take into account such factors as surface elevation, cloud cover, ozone abundance, and surface reflectivity (33).

Quintiles were created for the clinic center Langleys and Watts values. Quintile 1 contained the clinic centers with the greatest solar irradiance values and quintile 5 the least.

Individual Measures of Exposure Assessed at Year 4 Followup. In the fourth year of follow-up, participants completed questionnaires about $(a)$ the response of their skin to the sunlight when exposed for the first time in the summer for 45 to $60 \mathrm{~min}$, (b) the average time per day they spent outside during daylight hours in the summer and other seasons in the past year, and (c) whether or not they usually wore sunscreen in the past year when they were outside in the sunlight for $>10 \mathrm{~min}$. Data at year 4 follow-up were not available for all women in our sample of 71,662 . Thus, analyses on time spent outside and the response of skin to the sunlight reflect the smaller sample sizes (discussed below).

Statistical Analysis. Age-adjusted hazards ratios (HR) and $95 \%$ confidence intervals (CI) for breast cancer were estimated using Cox proportional-hazards models (34) among women residing in the following regions (outside the US, Northern, and Middle) compared with women residing in the Southern region at birth, age $15 \mathrm{y}$, age $35 \mathrm{y}$, and baseline. Age-adjusted HRs were estimated for breast cancer among women in quintiles 2 through 5 compared with quintile 1 for solar irradiance.

A number of covariates were included in the multivariate models (as shown in Table 1). The following covariates were included in the model as determined by stepwise regression (inclusion criteria of $P$ value of $<0.10$ and exclusion criteria of $P$ value of $>0.05$; ref. 35 ): age, weight, family history of breast cancer, age at menarche, age at menopause, parity, age at first birth, hormone therapy duration of use, and alcohol intake. Additionally, education, race/ethnicity, and physical activity were added to the model, although not identified by stepwise regression. These factors were significantly related to region of residence and incident breast cancer in this cohort and often cited in the literature as breast cancer risk factors.

Linear trends of associations between breast cancer and exposure variables were examined. Region of residence at baseline and solar irradiance variables were included in the model as continuous variables as each clinic center was assigned its own latitude and solar irradiance value. Linear trends for analyses with region of residence at birth, age $15 \mathrm{y}$, and age $35 \mathrm{y}$ were conducted using an ordinal variable assigned to the Northern, Middle, and Southern regions (excluding those living outside the United States). Additionally, the possibility that exposure variables could be related to breast cancer in a nonlinear function (e.g., quadratic or logarithmic) were explored, but no significant relationships were found.

We also evaluated whether or not the observed associations between breast cancer incidence and region of residence at baseline and clinic center solar irradiance differed by the following tumor characteristics: receptor status, tumor size, lymph node involvement, and tumor grade.
Analyses were conducted to investigate associations between average time reported spent outside per day in daylight hours (as an estimate of sun exposure at year 4 follow-up) and risk for breast cancer. We made the assumption that average time reported spent outside per day at year 4 was similar to the average amount of time women would have reported spending outside at baseline. Among the 71,662 women in the primary analyses, 63,622 and 63,496 answered questions about average time spent outside during the summer and other seasons, respectively. Adjusted HRs and 95\% CI were estimated for breast cancer among women who reported spending on average per day $<30$ and $30 \mathrm{~min}$ to 2 $\mathrm{h}$ compared with $>2 \mathrm{~h}$ outside during daylight hours in summer (and other seasons). Analyses were also repeated among women who reported the same amount of average time spent outside per day in both summer and other seasons, called year round. This sample consisted of 46,926 from the samples of 63,622 and 63,496 women with data on time times spent outside in summer and other seasons, respectively.

Associations between breast cancer risk and region of residence at baseline, solar irradiance, and average time reported spent outside per day year round were investigated for potential effect modification by the following factors: age, race/ethnicity, the Gail 5-y risk score, weight, body mass index, waist-to-hip ratio, recreational physical activity, total vitamin $\mathrm{D}$ intake, total calcium intake, total vitamin D and calcium intake (low vitamin $\mathrm{D} /$ low calcium, high vitamin $\mathrm{D} /$ low calcium, low vitamin $\mathrm{D} /$ high calcium, high vitamin D/ high calcium), region of residence at baseline, Langleys, Watts, participant's skin reaction to the sun as reported at year 4, and average time reported spent outside per day year round. Interactions were tested using the Likelihood Ratio test $(P$ value of $<0.05$ was considered statistically significant).

\section{Results}

Participant characteristics and breast cancer risk factors varied significantly by region of residence at baseline (Southern, Middle, and Northern; Table 1). However, breast cancer risk factors traditionally found to be associated with increased risk for breast cancer (e.g., family history of breast cancer, early age at menarche, nulliparity, etc.) were not consistently found to be more frequent in one region of residence compared with others. Results were similar when participant characteristics were stratified by quintiles of solar irradiance.

There was no association between breast cancer incidence and region of residence at birth, age $15 \mathrm{y}$, age $35 \mathrm{y}$, or baseline enrollment; or clinic center solar irradiance in the age-adjusted models (Table 2). After adjustment for additional covariates (multivariate model 1), there was an observed $15 \%$ decreased risk of breast cancer among women residing in areas of low compared with high solar irradiance (comparing quintile 5 to 1 ), assessed in Watts; however, the $P_{\text {trend }}$ was not significant $\left(P_{\text {trend }}=0.20\right)$. No association was observed between breast cancer and other measures of exposure. Further adjustment for intake of vitamin $\mathrm{D}$ from foods and supplements combined (multivariate model 2) did not greatly alter the observed HRs. Limiting the analyses for 
Table 1. Baseline (1993-1998) characteristics of participants in the WHIOS by region of residence at baseline among women included in the analysis of breast cancer incidence and geographic region of residence $(n=71,662)$

\begin{tabular}{|c|c|c|c|c|}
\hline & Southern & Middle & Northern & $P$ \\
\hline & $n(\%)$ & $n(\%)$ & $n(\%)$ & \\
\hline Age at baseline, $\mathrm{y}$ & & & & $<0.001$ \\
\hline $50-59$ & $8,779(35)$ & $4,795(35)$ & $10,074(31)$ & \\
\hline $60-69$ & $10,816(43)$ & $5,825(42)$ & $15,084(47)$ & \\
\hline $70-79$ & $5,759(23)$ & $3,275(24)$ & $7,255(22)$ & \\
\hline Race/ethnicity & & & & $<0.001$ \\
\hline Caucasian & $19,611(77)$ & $11,787(85)$ & $29,378(91)$ & \\
\hline African American & $1,908(8)$ & $1,172(8)$ & $1,989(6)$ & \\
\hline Hispanic & $1,731(7)$ & $271(2)$ & $421(1)$ & \\
\hline American Indian & $162(0.6)$ & $47(0.3)$ & $69(0.2)$ & \\
\hline Asian/Pacific Islander & $1,555(6)$ & $385(3)$ & $216(0.7)$ & \\
\hline Unknown & $387(2)$ & $233(2)$ & $340(1)$ & \\
\hline Education & & & & $<0.001$ \\
\hline $0-8 \mathrm{y}$ & $533(2)$ & $84(0.6)$ & $291(0.9)$ & \\
\hline Some high school & $867(3)$ & $326(2)$ & $1,001(3)$ & \\
\hline High school diploma/GED & 3,705 (15) & 1,652 (12) & 6,115 (19) & \\
\hline School after high school & $9,938(37)$ & $4,889(35)$ & $11,152(34)$ & \\
\hline College degree or higher & $10,311(41)$ & $6,944(50)$ & $13,854(43)$ & \\
\hline Family history of breast cancer & & & & $<0.001$ \\
\hline Yes & $4,342(17)$ & $2,540(18)$ & $6,021(19)$ & \\
\hline No & $19,922(79)$ & $10,726(77)$ & $25,072(77)$ & \\
\hline Missing & $1,090(4)$ & $629(5)$ & $1,320(4)$ & \\
\hline Age at menarche, $y$ & & & & 0.004 \\
\hline$\leq 11$ & $5,501(22)$ & $3,069(22)$ & $7,215(22)$ & \\
\hline $12-13$ & $13,946(55)$ & $7,806(56)$ & $17,948(55)$ & \\
\hline$\geq 14$ & $5,907(23)$ & $3,020(22)$ & $7,250(22)$ & \\
\hline Age at menopause, $y$ & & & & $<0.001$ \\
\hline $20-29$ & $258(1)$ & $102(0.7)$ & $144(0.4)$ & \\
\hline $30-39$ & $2,348(9)$ & $1,071(8)$ & $2,157(7)$ & \\
\hline $40-49$ & $10,525(42)$ & $5,368(39)$ & $11,957(37)$ & \\
\hline $50-60$ & $12,223(48)$ & $7,354(53)$ & $18,155(56)$ & \\
\hline Age at first birth, $y$ & & & & $<0.001$ \\
\hline Never pregnant & $2,383(9)$ & $1,432(10)$ & $3,281(10)$ & \\
\hline No term pregnancy & $770(3)$ & $445(3)$ & $701(2)$ & \\
\hline$<20$ & 3,439 (14) & $1,480(11)$ & 2,949 (9) & \\
\hline $20-24$ & $11,360(45)$ & $5,831(42)$ & $15,053(46)$ & \\
\hline $25-29$ & $5,623(22)$ & $3,449(25)$ & $7,941(25)$ & \\
\hline $30-34$ & $1,358(5)$ & $945(7)$ & $1,918(6)$ & \\
\hline $35-39$ & $3,56(1)$ & $269(2)$ & $478(1)$ & \\
\hline $40-44$ & $60(0.2)$ & $41(0.3)$ & $88(0.3)$ & \\
\hline $45+$ & $5(0.02)$ & $3(0.02)$ & $4(0.01)$ & \\
\hline No of term pregnancies & & & & $<0.001$ \\
\hline Never pregnant & $2,383(9)$ & $1,432(10)$ & $3,281(10)$ & \\
\hline Never had term pregnancy & $770(3)$ & $445(3)$ & $701(2)$ & \\
\hline 1 & $2,510(10)$ & $1,386(10)$ & $2,495(8)$ & \\
\hline 2 & $7,246(29)$ & $3,825(28)$ & $7,993(25)$ & \\
\hline 3 & $6,137(24)$ & $3,309(24)$ & $7,993(25)$ & \\
\hline 4 & 3,549 (14) & $1,924(14)$ & $4,965(15)$ & \\
\hline $5+$ & $2,759(11)$ & $1,574(11)$ & $4,985(15)$ & \\
\hline Weight quintiles, $\mathrm{kg}$ & & & & $<0.001$ \\
\hline Quintile 1: <58.7 & $5,647(22)$ & $2,786(20)$ & $5,870(18)$ & \\
\hline Quintile $2: \geq 58.7$ to $<65.0$ & $5,279(21)$ & $2,860(21)$ & $6,405(20)$ & \\
\hline Quintile $3: \geq 65.0$ to $<71.8$ & $4,926(19)$ & $2,747(20)$ & $6,511(20)$ & \\
\hline Quintile $4: \geq 71.8$ to $<81.9$ & 4,776 (19) & $2,725(20)$ & $6,742(21)$ & \\
\hline Quintile 5: $\geq 81.9$ & $4,726(19)$ & $2,777(20)$ & $6,885(21)$ & \\
\hline Body mass index, $\mathrm{kg} / \mathrm{m}^{2 *}$ & & & & $<0.001$ \\
\hline Underweight $(<18.5)$ & $377(2)$ & $166(1)$ & $302(0.9)$ & \\
\hline Normal ( $\geq 18.5$ to 24.9$)$ & $10,843(43)$ & $5,884(43)$ & $12,155(38)$ & \\
\hline Overweight (25.0-29.9) & $8,369(33)$ & $4,549(33)$ & $11,361(35)$ & \\
\hline Obesity I (30.0-34.9) & 3,571 (14) & $2,014(15)$ & $5,277(16)$ & \\
\hline Obesity II (35.0-39.9) & 1,247 (5) & $722(5)$ & $2,023(6)$ & \\
\hline Extreme obesity III $(\geq 40)$ & $785(3)$ & $446(3)$ & $1,106(3)$ & \\
\hline $\begin{array}{l}\text { Recreational Physical activity quintiles, } \\
\text { MET } h / w k\end{array}$ & & & & $<0.001$ \\
\hline Quintile $1:<2.0$ & $5,519(22)$ & $2,432(18)$ & $6,491(20)$ & \\
\hline Quintile $2: \geq 2.0$ to $<7.2$ & 4,859 (19) & 2,635 (19) & $6,595(20)$ & \\
\hline Quintile $3: \geq 7.2$ to $<13.5$ & $5,082(20)$ & $2,873(21)$ & $6,764(21)$ & \\
\hline Quintile $4: \geq 13.5$ to $<23.3$ & $4,823(19)$ & $2,941(21)$ & $6,525(20)$ & \\
\hline
\end{tabular}


Table 1. Baseline (1993-1998) characteristics of participants in the WHIOS by region of residence at baseline among women included in the analysis of breast cancer incidence and geographic region of residence $(n=71,662)(C o n t ' d)$

\begin{tabular}{|c|c|c|c|c|}
\hline & Southern & Middle & Northern & $P$ \\
\hline & $n(\%)$ & $n(\%)$ & $n(\%)$ & \\
\hline Quintile $5: \geq 23.3$ & $5,071(20)$ & $3,014(22)$ & $6,038(19)$ & \\
\hline Hormone therapy duration of use, $y$ & & & & $<0.001$ \\
\hline None & $7,278(29)$ & $4,242(31)$ & $14,714(45)$ & \\
\hline$<5$ & $5,872(23)$ & $3,394(24)$ & $7,100(22)$ & \\
\hline 5 to $<10$ & 4,089 (16) & $2,204(16)$ & $4,160(13)$ & \\
\hline $10+$ & $8,115(32)$ & $4,055(29)$ & $6,439(20)$ & \\
\hline Alcohol intake & & & & $<0.001$ \\
\hline Nondrinker & $4,084(16)$ & $1,145(8)$ & $2,407(7)$ & \\
\hline Past drinker & 4,897 (19) & $2,427(17)$ & $5,483(17)$ & \\
\hline$<1$ drink per month & 2,717 (11) & $1,503(11)$ & 4,092 (13) & \\
\hline$<1$ drink per week & 4,615 (18) & $2,827(20)$ & $7,035(22)$ & \\
\hline 1 to $<7$ drinks per week & $5,886(23)$ & $3,829(28)$ & $9,303(29)$ & \\
\hline $7+$ drinks per week & $3,155(12)$ & $2,164(16)$ & 4,093 (13) & \\
\hline $\begin{array}{l}\text { Vitamin } \mathrm{D} \text { intake from foods quintiles, } \\
\text { energy adjusted IU /d }\end{array}$ & & & & $<0.001$ \\
\hline Quintile 1: $<88.0$ & $5,708(23)$ & $2,917(21)$ & $5,707(18)$ & \\
\hline Quintile $2: \geq 88.0$ to $<123.7$ & $5,386(21)$ & $2,848(21)$ & $6,099(19)$ & \\
\hline Quintile $3: \geq 123.7$ to $<163.9$ & 5,191 (20) & $2,774(20)$ & $6,367(20)$ & \\
\hline Quintile $4: \geq 163.9$ to $<227.7$ & $4,776(19)$ & $2,740(20)$ & $6,817(21)$ & \\
\hline Quintile 5: $\geq 227.7$ & $4,293(17)$ & $2,616(19)$ & $7,423(23)$ & \\
\hline $\begin{array}{l}\text { Vitamin D intake from foods and supplements } \\
\text { quintiles, energy adjusted IU/d }\end{array}$ & & & & $<0.001$ \\
\hline Quintile 1: <123.4 & $5,765(23)$ & $2,798(20)$ & $5,769(18)$ & \\
\hline Quintile $2: \geq 123.4$ to $<222.7$ & $5,094(20)$ & $2,704(19)$ & $6,535(20)$ & \\
\hline Quintile $3: \geq 222.7$ to $<450.6$ & $4,574(18)$ & $2,864(21)$ & $6,894(21)$ & \\
\hline Quintile $4: \geq 450.6$ to $<622.8$ & $4,864(19)$ & $2,841(20)$ & $6,628(20)$ & \\
\hline Quintile 5: $\geq 622.8$ & $5,057(20)$ & $2,688(19)$ & $6,587(20)$ & \\
\hline
\end{tabular}

NOTE: $P$ value from a $\chi^{2}$ test comparing baseline characteristics by region of residence at baseline.

*There is missing data for these variables, resulting in $n$ s that do not add up to 71,662 . Missing persons were not included in $\chi$.

region of residence at baseline and solar irradiance to women who had lived at their current residence for $\geq 20$ years $(n=60,337)$ did not change the results for region of residence at baseline or Langleys (data not shown), but the statistically significant relationship observed with Watts no longer remained: HR $(95 \% \mathrm{CI})=0.88(0.75-1.04)$ for low compared with high solar irradiance, associated $P_{\text {trend }}$ of 0.51 . Excluding women who had moved clinic centers during the course of WHIOS $(n=6,082)$ did not alter the results (data not shown). When the analysis for breast cancer and region of residence was limited to women who had lived in the same region of residence at birth, age 15 years, age 35 years, and baseline $(n=$ $33,617)$, the relationship was null: $\mathrm{HR}(95 \% \mathrm{CI})$ for Middle [1.07 (0.90-1.27)] and Northern [0.97 (0.83-1.14)] compared with Southern.

Analyses were also stratified by tumor characteristics (Table 3). There was a statistically significant decreased risk of the following tumors among women residing in Northern/low solar irradiance areas compared with Southern/high solar irradiance areas: PR-, ER+/PR-, large $(>5 \mathrm{~cm})$, no lymph node involvement, and welldifferentiated to moderately differentiated. These results were not consistent across all exposure categories. There also seemed to be an increased risk of anaplastic tumors among women living at Northern versus Southern regions, but these results were not statistically significant and the number of cases was small.

Analyses were conducted using data from year 4 follow-up questionnaires to investigate associations between average reported time spent outside in daylight hours per day and risk for breast cancer (Table 4). Women who reported spending on average $<30$ minutes compared with $>2 \mathrm{~h}$ outside in daylight hours in summer, other seasons, or year round had an $18 \%$, $23 \%$, and $20 \%$ increased risk of breast cancer, respectively. Adjustment for reported use of sunscreen did not alter the significance of the observed HRs (data not shown).

The relationships between breast cancer incidence and region of residence at baseline, solar irradiance, or average reported time spent outside per day year round did not vary significantly by age, Gail 5-year risk score, weight, body mass index, waist-to-hip ratio, physical activity, or intake of vitamin D or calcium.

Results for region of residence, solar irradiance, and average time reported spent outside per day year round are presented stratified by the reaction of the skin to the sun (Fig. 1). The relationship between breast cancer and Watts was modified by the reaction of the skin to the sun $\left(P_{\text {interaction }}=0.03\right)$. Among individuals with selfreported no change in skin color or ability to tan (not burn), a reduction in risk was observed among individuals living in low compared with high solar irradiance areas (assessed in Watts). Figure 1 also shows that there seemed to be an increased risk of breast cancer, although not always statistically significant, among women who reported spending $<30$ minutes compared with $>2$ hours outside year round for most skin types with the exception of women who burned (no tan). 
Table 2. HRs and $95 \% \mathrm{Cls}$ for incident breast cancer by region of residence at birth, age $15 \mathrm{y}$, age $35 \mathrm{y}$, and baseline (1993-1998); and solar irradiance values in Langleys and Watts: the WHIOS $(n=71,662)$

\begin{tabular}{|c|c|c|c|c|c|c|c|}
\hline Exposure & $\begin{array}{l}\text { Breast cancer } \\
\text { cases }\end{array}$ & $n$ & $\begin{array}{l}\text { Person-years } \\
\text { of follow-up } \\
(\times 1,000)\end{array}$ & $\begin{array}{l}\text { Annualized } \\
\text { rate }(\%)\end{array}$ & $\begin{array}{l}\text { Age-adjusted } \\
\text { HR (95\% CI) }\end{array}$ & $\begin{array}{l}\text { Multivariate } \\
\text { model } 1^{*} \\
\text { HR }(95 \% \text { CI })\end{array}$ & $\begin{array}{l}\text { Multivariate } \\
\text { model } 2 \uparrow \\
\text { HR }(95 \% \text { CI) }\end{array}$ \\
\hline \multicolumn{8}{|l|}{ Region at birth $^{\ddagger}$} \\
\hline Southern & 455 & 13,819 & 112 & 0.40 & 1.0 & 1.0 & 1.0 \\
\hline Middle & 885 & 23,958 & 204 & 0.43 & $1.08(0.97-1.21)$ & $0.98(0.87-1.10)$ & $0.98(0.87-1.10)$ \\
\hline Northern & 1,010 & 28,118 & 239 & 0.42 & $1.04(0.94-1.17)$ & $0.95(0.84-1.07)$ & $0.95(0.84-1.07)$ \\
\hline Not United States & 162 & 5,021 & 41 & 0.39 & $0.97(0.81-1.16)$ & $1.00(0.83-1.20)$ & $1.00(0.83-1.20)$ \\
\hline$P_{\text {trend }} \$$ & & & & & 0.63 & 0.41 & 0.40 \\
\hline \multicolumn{8}{|l|}{ Region at age $15 \mathrm{y}^{\S}$} \\
\hline Southern & 433 & 13,325 & 109 & 0.40 & 1.0 & 1.0 & 1.0 \\
\hline Middle & 932 & 25,106 & 213 & 0.44 & $1.11(0.99-1.24)$ & $1.02(0.90-1.14)$ & $1.02(0.90-1.14)$ \\
\hline Northern & 1,027 & 28,402 & 241 & 0.43 & $1.07(0.95-1.20)$ & $1.00(0.88-1.12)$ & $1.00(0.88-1.12)$ \\
\hline Not United States & 127 & 4,196 & 34 & 0.37 & $0.93(0.76-1.13)$ & $0.97(0.79-1.19)$ & $0.97(0.79-1.19)$ \\
\hline \multirow{2}{*}{\multicolumn{8}{|c|}{$\begin{array}{l}\text { trend } \\
\text { Region at age } 35 \mathrm{y}^{\S}\end{array}$}} \\
\hline & & & & & & & \\
\hline Southern & 485 & 13,725 & 113 & 0.43 & 1.0 & 1.0 & 1.0 \\
\hline Middle & 1,025 & 28,699 & 243 & 0.42 & $0.98(0.88-1.09)$ & $0.92(0.82-1.02)$ & $0.92(0.82-1.02)$ \\
\hline Northern & 932 & 26,169 & 221 & 0.42 & $0.96(0.86-1.07)$ & $0.92(0.82-1.03)$ & $0.92(0.82-1.03)$ \\
\hline Not United States & 77 & 2,240 & 18 & 0.42 & $0.96(0.76-1.22)$ & $0.95(0.75-1.21)$ & $0.95(0.75-1.21)$ \\
\hline$P_{\text {trend }}$ & & & & & 0.47 & 0.23 & 0.23 \\
\hline \multicolumn{8}{|l|}{ Region at baseline } \\
\hline Southern & 869 & 25,354 & 209 & 0.42 & 1.0 & 1.0 & 1.0 \\
\hline Middle & 548 & 13,895 & 118 & 0.46 & $1.12(1.01-1.25)$ & $1.06(0.95-1.18)$ & $1.06(0.95-1.18)$ \\
\hline Northern & 1,118 & 32,413 & 275 & 0.41 & $0.98(0.89-1.07)$ & $0.97(0.89-1.07)$ & $0.97(0.89-1.07)$ \\
\hline \multirow{2}{*}{\multicolumn{8}{|c|}{$\begin{array}{l}P_{\text {trend }} \\
\text { Clinic center Langleys }(\mathrm{gm}-\mathrm{cal}) \text { per } \mathrm{cm}^{2}\end{array}$}} \\
\hline & & & & & & & \\
\hline $475-500$ & 555 & 15,338 & 127 & 0.44 & 1.0 & 1.0 & 1.0 \\
\hline $400-430$ & 431 & 12,339 & 103 & 0.42 & $0.97(0.85-1.10)$ & $0.93(0.82-1.06)$ & $0.93(0.82-1.06)$ \\
\hline $375-380$ & 299 & 8,009 & 67 & 0.44 & $1.04(0.90-1.20)$ & $1.00(0.87-1.16)$ & $1.00(0.87-1.16)$ \\
\hline 350 & 518 & 15,234 & 127 & 0.41 & $0.93(0.83-1.05)$ & $0.94(0.83-1.06)$ & $0.94(0.83-1.06)$ \\
\hline $300-325$ & 732 & 20,742 & 178 & 0.41 & $0.95(0.85-1.06)$ & $0.93(0.83-1.05)$ & $0.93(0.83-1.05)$ \\
\hline \multirow{2}{*}{\multicolumn{8}{|c|}{$\begin{array}{l}P_{\text {trend }} \\
\text { Clinic center Watts }(\mathrm{J} / \mathrm{s}) \text { per } \mathrm{m}^{2}\end{array}$}} \\
\hline & & & & & & & \\
\hline $1.5-1.9$ & 350 & 9,655 & 80 & 0.44 & 1.0 & 1.0 & 1.0 \\
\hline 1.4 & 562 & 16,369 & 136 & 0.41 & $0.93(0.82-1.07)$ & $0.85(0.74-0.97)$ & $0.85(0.74-0.97)$ \\
\hline 1.0 & 519 & 13,258 & 111 & 0.47 & $1.06(0.92-1.21)$ & $0.96(0.83-1.10)$ & $0.96(0.83-1.10)$ \\
\hline 0.7 & 556 & 15,730 & 135 & 0.41 & $0.95(0.83-1.08)$ & $0.88(0.77-1.02)$ & $0.88(0.77-1.01)$ \\
\hline $0.4-0.5$ & 548 & 16,650 & 140 & 0.39 & $0.89(0.78-1.02)$ & $0.85(0.74-0.98)$ & $0.85(0.74-0.98)$ \\
\hline$P_{\text {trend }}$ & & & & & 0.23 & 0.20 & 0.20 \\
\hline
\end{tabular}

*Adjusted for age, race/ethnicity, education, weight, family history of breast cancer, age at menarche, age at menopause, parity, age at first birth, hormone therapy duration of use, alcohol intake, and recreational physical activity.

† Adjusted for all covariates in multivariate model 1 plus adjustment for vitamin D intake from foods and supplements (energy adjusted IU/d).

¥ Some persons were missing data for region of residence at birth, and ages 15 and $35 \mathrm{y}$. Total $n$ for analyses by region of residence at birth is 70,916 , at age $15 \mathrm{y}$ is 71,029 and at age $35 \mathrm{y}$ is 70,833 .

$\S$ A test for trend was conducted using ordinal variable assigned to Southern, Middle and Northern for region at birth, age 15 and age $35 \mathrm{y}$ (excluding those living outside the United States.). A test for trend was conducted using continuous variable for region at baseline, Langleys, and Watts.

Results are also presented stratified by race/ethnicity (Fig. 2). Results in Caucasians were similar to what was observed in the overall analysis. Among African Americans, a $34 \%$ reduction in risk (associated $P_{\text {trend }}=0.08$ ) was observed among those living at Northern compared with the Southern regions. A significant trend for decreasing risk of breast cancer with decreasing solar irradiance was also observed among African Americans $\left(P_{\text {trend }}=0.04\right.$ for Langleys and Watts). Lastly, there seemed to be an increase risk of breast cancer (albeit not statistically significant) among women who spent $<30$ minutes compared with $>2$ hours outside year round regardless of race/ethnicity.

The relationship between breast cancer and region of residence and solar irradiance are presented stratified by average reported time spent outside per day (Fig. 3). The relationship between breast cancer and Langleys was modified by average reported time spent outside per day year round $\left(P_{\text {interaction }}=0.047\right)$. Risk for breast cancer among women residing in low compared with high solar irradiance areas, assessed in Langleys, decreased with increasing reported time spent outside. However, none of the HRs were statistically significant. Also observed was a decreased risk of breast among women residing in low compared with high solar irradiance areas, assessed in Watts, among those who reported spending on average 30 minutes to 2 hours outside. This relationship did not remain among those who reported spending $>2$ hours outside.

Figure 4 illustrates the relationship between breast cancer risk and average reported time spent outside per day year round stratified by region of residence and solar irradiance. Almost all HRs for risk of breast cancer among women who reported spending $<30$ minutes outside compared with $>2$ hours were $>1.0$ regardless of region of residence based on latitude or solar irradiance exposure.

Results presented in Figs. 1 through 4 did not vary when these analyses, involving reported time spent 
Table 3. Adjusted HRs and $95 \%$ Cls for incident breast cancer by region of residence at baseline (Southern vs Northern residence) and solar irradiance (low vs high solar exposure) stratified by breast cancer tumor characteristics: the WHIOS $(n=71,662)$

\begin{tabular}{|c|c|c|c|c|}
\hline & Cases & $\begin{array}{l}\text { Northern }\left(>40^{\circ}\right) \text { vs } \\
\text { Southern }\left(\leq 37^{\circ}\right)\end{array}$ & $\begin{array}{c}\text { Langleys (gm-cal) per cm }{ }^{2} \\
(300-325 \text { vs } 475-500)\end{array}$ & $\begin{array}{r}\text { Watts }(\mathrm{J} / \mathrm{s}) \text { per } \mathrm{m}^{2} \\
(0.4-0.5 \text { vs } 1.5-1.9)\end{array}$ \\
\hline \multicolumn{5}{|l|}{ ER status } \\
\hline ER+ & 1,932 & $1.02(0.92,1.13)$ & $0.97(0.86,1.11)$ & $0.86(0.73,1.01)$ \\
\hline ER- & 346 & $0.97(0.76,1.25)$ & $0.90(0.65,1.25)$ & $1.00(0.69,1.46)$ \\
\hline \multicolumn{5}{|l|}{ PR status } \\
\hline $\mathrm{PR}+$ & 1,607 & $1.07(0.95,1.20)$ & $1.08(0.94,1.25)$ & $0.90(0.75,1.08)$ \\
\hline PR- & 634 & $0.90(0.75,1.08)$ & $0.71(0.56,0.90)$ & $0.79(0.61,1.04)$ \\
\hline \multicolumn{5}{|l|}{$\mathrm{ER} / \mathrm{PR}$ status } \\
\hline $\mathrm{ER}+/ \mathrm{PR}+$ & 1,572 & $1.07(0.96,1.21)$ & $1.09(0.94,1.26)$ & $0.90(0.75,1.08)$ \\
\hline $\mathrm{ER}+/ \mathrm{PR}-$ & 322 & $0.83(0.64,1.07)$ & $0.59(0.42,0.82)$ & $0.64(0.45,0.93)$ \\
\hline $\mathrm{ER}-/ \mathrm{PR}+$ & 35 & $0.77(0.36,1.67)$ & $0.83(0.30,2.33)$ & $0.79(0.25,2.48)$ \\
\hline $\mathrm{ER}-/ \mathrm{PR}-$ & 305 & $1.00(0.77,1.30)$ & $0.90(0.63,1.27)$ & $1.01(0.68,1.52)$ \\
\hline \multicolumn{5}{|l|}{ Tumor size (cm) } \\
\hline$<0.5$ & 186 & $1.04(0.73,1.47)$ & $0.96(0.60,1.53)$ & $1.49(0.84,2.66)$ \\
\hline $0.5-1$ & 475 & $1.20(0.97,1.49)$ & $1.02(0.79,1.33)$ & $0.96(0.69,1.33)$ \\
\hline$>1$ to 2 & 982 & $0.90(0.78,1.05)$ & $0.88(0.73,1.05)$ & $0.75(0.60,0.93)$ \\
\hline$>2$ to 5 & 497 & $1.09(0.89,1.35)$ & $1.03(0.79,1.35)$ & $0.98(0.70,1.35)$ \\
\hline$>5$ & 86 & $0.49(0.30,0.79)$ & $0.45(0.26,0.80)$ & $0.49(0.23,1.03)$ \\
\hline \multicolumn{5}{|l|}{ Lymph node involvement } \\
\hline No & 1,817 & $1.00(0.89,1.11)$ & $0.99(0.87,1.13)$ & $0.84(0.71,0.99)$ \\
\hline Yes & 610 & $0.92(0.79,1.06)$ & $0.82(0.65,1.04)$ & $0.80(0.60,1.06)$ \\
\hline \multicolumn{5}{|l|}{ Tumor grade } \\
\hline Well-differentiated & 631 & $0.93(0.77,1.12)$ & $0.74(0.59,0.92)$ & $0.53(0.40,0.70)$ \\
\hline Moderately differentiated & 972 & $0.92(0.79,1.06)$ & $0.97(0.81,1.16)$ & $0.78(0.62,0.98)$ \\
\hline Poorly differentiated & 567 & $1.15(0.95,1.41)$ & $1.23(0.95,1.60)$ & $1.30(0.94,1.80)$ \\
\hline Anaplastic & 64 & $1.50(0.84,2.68)$ & $1.06(0.51,2.22)$ & $1.46(0.67,3.17)$ \\
\hline
\end{tabular}

NOTE: Adjusted for age, race/ethnicity, education, weight, family history of breast cancer, age at menarche, age at menopause, parity, age at first birth, hormone therapy duration of use, alcohol intake, and physical activity.

outside per day, were repeated using data restricted to time spent outside per day in just summer or other seasons (data not shown).

\section{Discussion}

In the WHIOS we observed, no consistent evidence that region of residence or regional solar irradiance was related to risk of incident invasive breast cancer. Regions of residence at other time points (birth, age $15 \mathrm{y}$, age $35 \mathrm{y}$ ) were not associated with breast cancer risk. However, analyses showed an increased risk of breast cancer among women reporting $<30$ minutes compared with $>2$ hours of average time spent outside. Additionally, adjustment for individual level risk factors had very little effect on the hazard ratio estimates.

Contrary to our expectations, we observed that low compared with high solar irradiance exposure, assessed as Watts, was related to reduced risk of breast cancer. However, this result was not confirmed by region of residence at baseline or solar irradiance measured in Langleys, lending less strength to the plausibility that low solar irradiance is protective against breast cancer.

Table 4. Adjusted HRs and $95 \%$ Cls for incident breast cancer among women who reported spending < 30 or 30 min to $2 \mathrm{~h}$ compared with $>2 \mathrm{~h}$ outside in daylight hours in the summer, in the other seasons, and all year: the WHIOS

\begin{tabular}{|c|c|c|c|c|c|c|}
\hline \multirow{3}{*}{$\frac{\text { Average reported time spent outside }}{\text { Total at risk (breast cancer cases) }}$} & \multicolumn{2}{|c|}{ In summer } & \multicolumn{2}{|c|}{ In other seasons } & \multicolumn{2}{|c|}{ Year round* } \\
\hline & \multicolumn{2}{|c|}{$63,622^{\dagger}(2,316)$} & \multicolumn{2}{|c|}{$63,496^{\dagger}(2,315)$} & \multicolumn{2}{|c|}{$46,926^{\dagger}(1,753)$} \\
\hline & \#cases $/ n$ & $\operatorname{HR}(95 \%$ CI) & $\#$ cases $/ n$ & HR $(95 \%$ CI) & \#cases/n & HR (95\% CI) \\
\hline $\begin{array}{l}>2 \mathrm{~h} \\
30 \mathrm{~min} \text { to } 2 \mathrm{~h} \\
<30 \min _{\mp} \\
P_{\text {trend }}\end{array}$ & $\begin{array}{r}407 / 12,035 \\
1,095 / 31,590 \\
814 / 19,997\end{array}$ & $\begin{array}{c}1.0 \\
0.99(0.89,1.12) \\
1.18(1.05,1.34) \\
0.001\end{array}$ & $\begin{array}{r}\text { 230/7,237 } \\
1,117 / 32,168 \\
968 / 24,091\end{array}$ & $\begin{array}{c}1.0 \\
1.05(0.91,1.22) \\
1.23(1.06,1.42) \\
0.0004\end{array}$ & $\begin{array}{l}203 / 6,029 \\
840 / 23,962 \\
710 / 16,935\end{array}$ & $\begin{array}{cl}1.0 \\
0.99 & (0.85,1.16) \\
1.20 & (1.02,1.41) \\
& 0.001\end{array}$ \\
\hline
\end{tabular}

NOTE: HRs adjusted for age, race/ethnicity, education, weight, family history, age at menarche, age at menopause, parity, age at first birth, hormone therapy duration of use, alcohol consumption, and physical activity.

* Reported average time spent outside in daylight hours per day year round is defined as those women who responded spending the same average amount of time outside in daylight hours per day in summer and in other seasons at year four follow-up.

† The sample sizes are less than the starting sample of 71,662. Not all women answered questions regarding time spent outdoors at year 4 or women were lost to follow-up.

$\ddagger$ A test for trend was conducted for average time per day spent outside year round using ordinal variables assigned to $<30$, 30 min to $2 \mathrm{~h}$, and $>2 \mathrm{~h}$. 


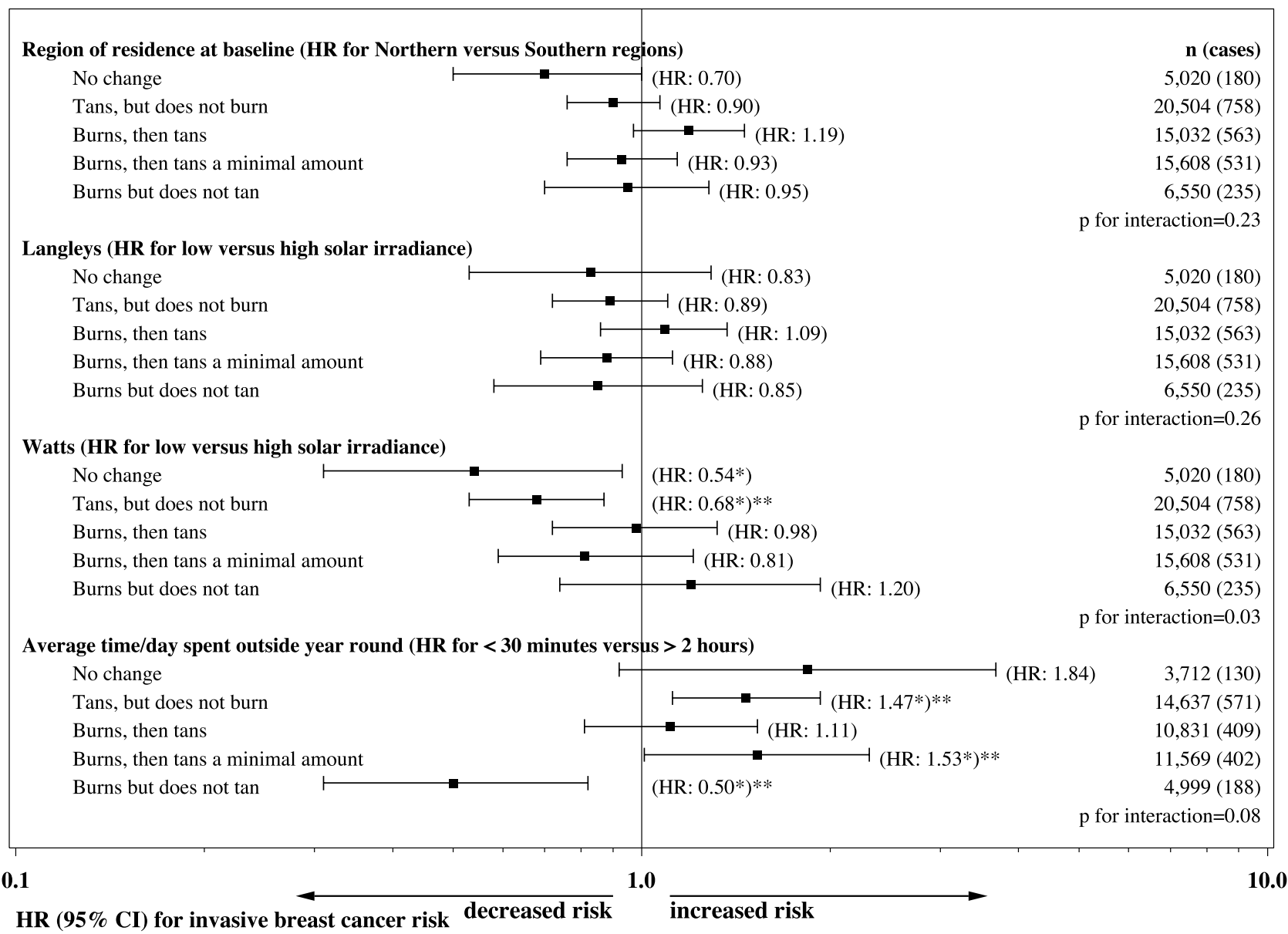

Figure 1. Adjusted (adjusted for age, race/ethnicity, education, weight, family history of breast cancer, age at menarche, age at menopause, parity, age at first birth, hormone therapy duration of use, alcohol intake, and recreational physical activity) HRs and $95 \%$ CIs for incident breast cancer by region of residence at baseline, solar irradiance, and time reported spent outside year round at year 4 follow-up stratified by the reaction of the skin to the sun: the WHIOS. $*, 95 \%$ CI does not include $1.0 .^{* *}, P_{\text {trend }}<0.05$; A test for trend was conducted using continuous variables for region of residence at baseline, Langleys, and Watts; A test for trend was conducted for average time per day spent outside year round using ordinal variables assigned to $<30,30 \mathrm{~min}$ to $2 \mathrm{~h}$.

Differences between the solar irradiance measures of Langleys and Watts may explain the inconsistent results. Langleys is a measure of mean annual total solar irradiance over a number of years, whereas the Watts was a measure of UVB solar irradiance assessed over 1 year (1989). Therefore, clinic centers could be classified slightly differently based on whether Langleys or Watts was used for the solar irradiance unit. Fluctuations in UVB solar irradiance from year to year, as opposed to an average of total solar irradiance over time, may have resulted in a spurious finding with Watts. Neither measure of Langleys or Watts is a perfect measure of the relevant UVB exposure to assess vitamin D synthesis.

Other studies in the United States have investigated associations between incident breast cancer and region of residence or measures of regional solar irradiance with varied results. A recent study, by Boscoe et al. (6), investigated associations between incident breast cancer in North America among Caucasians and African Americans. They observed, in both races, an increased risk of incident breast cancer with decreasing amounts of average annual solar UVB light exposure. They adjusted for breast cancer risk factors, but most were assessed at the county or state level.

Two previously conducted studies were closer in design to the WHIOS $(14,15)$. In a prospective study with nationally representative data (15), a borderline statistically significant lower risk for incident breast cancer (relative risk, $0.71 ; 95 \% \mathrm{CI}, 0.47-1.09$ ) was found among women residing in the South compared with the Northeast between 1971 and 1975. In a different cohort, data from the Nurses' Health Study (14) was used to investigate associations between incident breast cancer and region of residence (using 11 US states): Northeast, Midwest, South, and California. After adjusting for covariates, they only observed an increased risk of breast cancer among women residing, for an extended period of time, in California versus the South. The Nurses' Health Study results are most similar to ours, as they did not see increased risk of breast cancer in the Northeast compared with the South. However, neither previous study investigated associations between incident breast cancer 
and measures of solar irradiance by region or created residential regions based primarily on latitude.

More studies on region of residence and measures of solar irradiance have looked at associations with breast cancer mortality than incidence. All have shown evidence of an inverse relationship between cancer mortality and residence at lower latitudes or increased solar irradiance $(1-4,7,16,17,36)$. We may not have observed an association between latitude/solar irradiance and incident breast cancer if vitamin D exposure affects breast cancer survival more so than preventing cancer incidence, as suggested by Boscoe et al. (6). Currently, there are too few breast cancer deaths $(n=126)$ in WHIOS to investigate mortality.

In our study, we observed a decreased risk (albeit not always statistically significant) of $\mathrm{PR}-, \mathrm{ER}+/ \mathrm{PR}-$, large $(>5 \mathrm{~cm})$, and well-differentiated tumors among women living at Northern/low solar irradiance compared with Southern/high solar irradiance areas. A decreased risk of large tumors suggested that perhaps Northern, com- pared with Southern regions, may reflect regional differences in screening leading to differences in the likelihood of detection of earlier cancers. However, we observed minimal differences $(<2 \%)$ in the frequency of women reporting mammography in the WHIOS by region to support this hypothesis. We observed less well-differentiated, and more anaplastic, breast cancers at Northern versus Southern latitudes. This supports the hypothesis that vitamin D promotes cell differentiation (10), with a greater likelihood of less differentiated tumors, perhaps with worse survival, in regions with less solar irradiance. However, we can offer no explanation as to why a decreased risk of $\mathrm{PR}-$ or ER+/PRbreast cancers would be observed in Northern compared with Southern regions. At the same time, it is possible that these observations are spurious findings.

Our analysis, when limited to individuals with skin types that do not change or tan (no burn; i.e., darker pigmentation) upon exposure to sunlight, suggests that residing at Northern/low solar irradiance compared

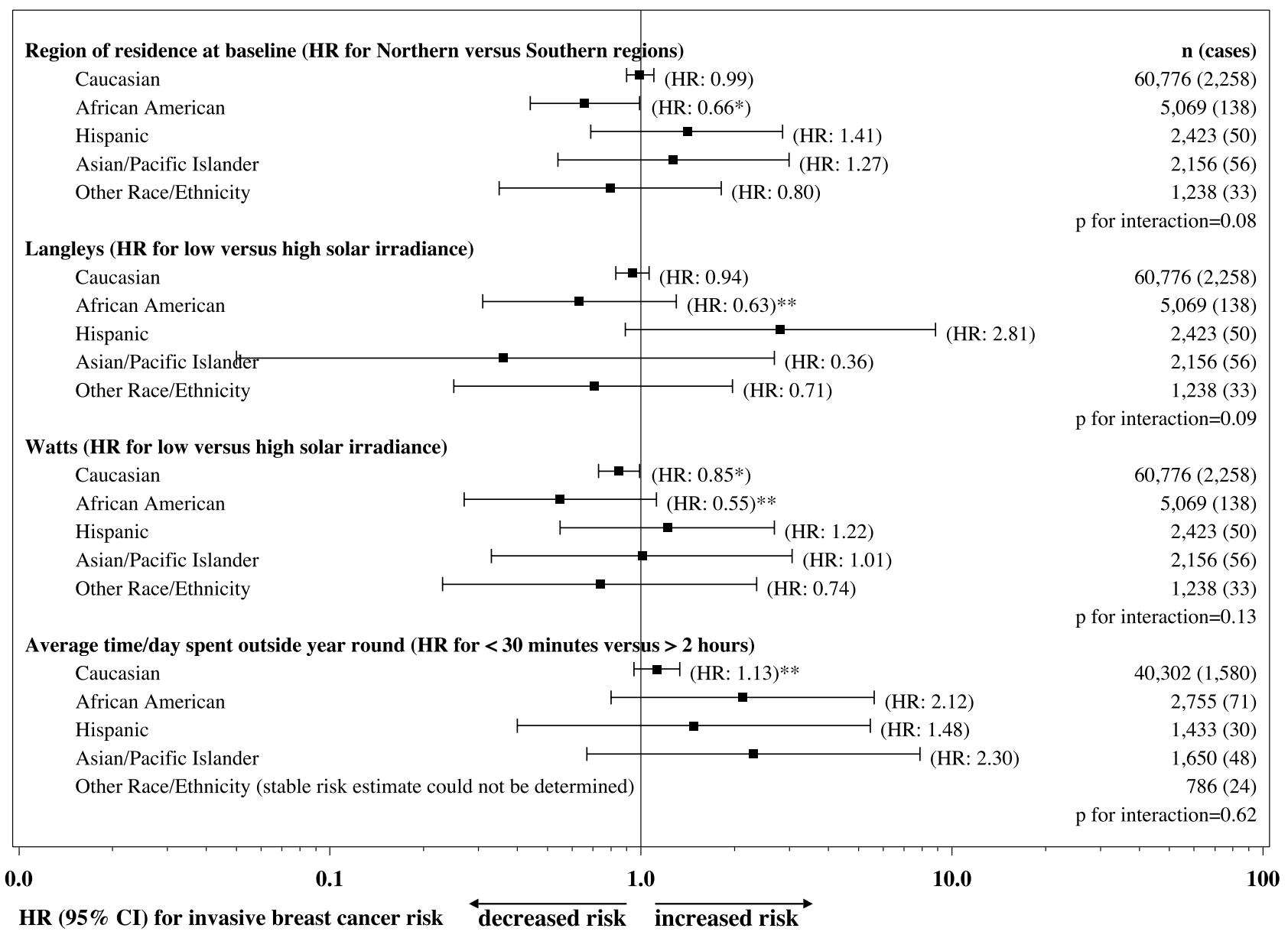

Figure 2. Adjusted (adjusted for age, race/ethnicity, education, weight, family history of breast cancer, age at menarche, age at menopause, parity, age at first birth, hormone therapy duration of use, alcohol intake, and recreational physical activity) HR and $95 \%$ CIs for incident breast cancer by region of residence at baseline, solar irradiance, and time reported spent outside year round at year 4 follow-up stratified by race/ethnicity: the WHIOS. *, 95\% CI does not include $1.0 .{ }^{* *}, P_{\text {trend }}<0.05$; A test for trend was conducted using continuous variables for region of residence at baseline, Langleys, and Watts; A test for trend was conducted for average time per day spent outside year round using ordinal variables assigned to $<30,30 \mathrm{~min}$ to $2 \mathrm{~h}$, and $>2 \mathrm{~h}$. 


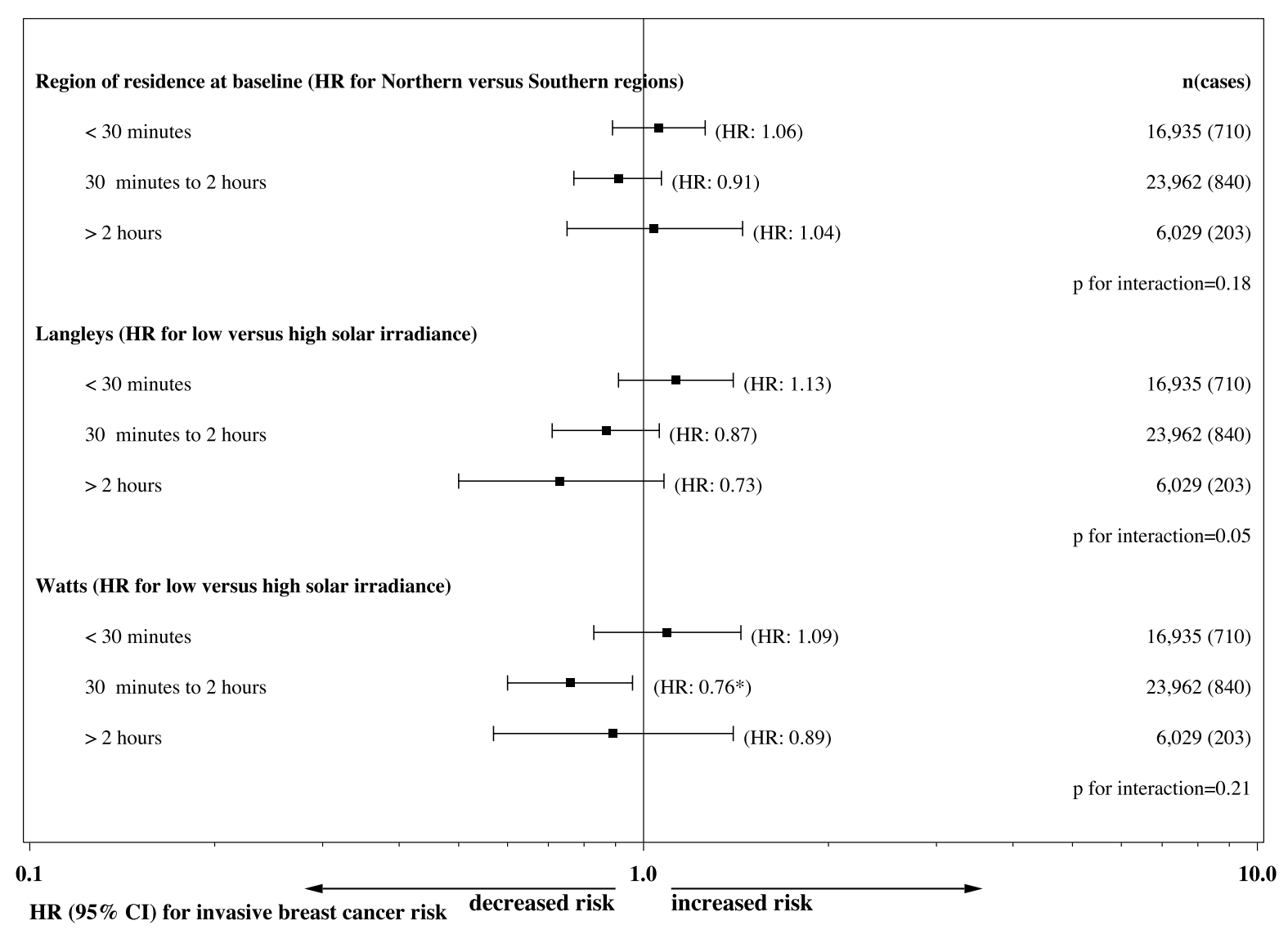

Figure 3. Adjusted (adjusted for age, race/ethnicity, education, weight, family history of breast cancer, age at menarche, age at menopause, parity, age at first birth, hormone therapy duration of use, alcohol intake, and recreational physical activity) HRs and 95\% CIs for incident breast cancer by region of residence at baseline and solar irradiance stratified by average time per day spent outside year round: the WHIOS. *, 95\% CI does not include 1.0. ${ }^{* *}, P_{\text {trend }}<0.05$; A test for trend was conducted using continuous variables for region of residence at baseline, Langleys, and Watts; A test for trend was conducted for average time per day spent outside year round using ordinal variables assigned to $<30,30 \mathrm{~min}$ to $2 \mathrm{~h}$.

with Southern/high solar irradiance areas may decrease risk for breast cancer among those subgroups. Similar results were observed for African Americans. It is unclear whether these results are explained more by skin type or race/ethnicity. These results were unexpected. If vitamin $\mathrm{D}$ does prevent breast cancer incidence, one would expect that risk would be greater among individuals with darker pigmented skin living at Northern compared with Southern latitudes. Individuals with darker pigmented skin require even longer periods of sun exposure to make the same amount of vitamin D in their skin as lighter pigmented individuals (9).

However, we did not observe a decreased risk of breast cancer among darker pigmented and African American individuals who reported spending on average less compared with more time outside during daylight hours. The HRs were $>1.0$, with the exception of individuals with the fairest skin (those who did not tan). This is different from results by John et al. (37) who observed the most protection from sun exposure among light pigmented compared with dark pigmented individuals. These observations make it less plausible that a decreased risk of breast cancer among darker pigmented individuals or African Americans residing in the North compared with the South is explained by exposure to sunlight and perhaps vitamin D.

The lack of association observed in the overall WHIOS between breast cancer incidence and region or residence and regional solar irradiance suggests that theses measures may not be valid surrogate markers for an individual's vitamin D status, at least in the United States or within the WHIOS. Women in the WHIOS are more highly educated than the general population and may practice more sun avoidance behavior than the general public. Region of residence alone may not sufficiently predict an individual's sun seeking or avoiding behavior.

Additional analyses in our study suggested that measurements of individual's time spent outside, as an estimate of sun exposure, are related significantly to breast cancer risk. These observations support the hypothesis that vitamin D exposure, via sufficient sun exposure, may be associated with protection against development of breast cancer. Prior research in a prospective cohort study (15) and case-control studies $(3,37,38)$ have also shown decreased risk of breast cancer with measures of self-reported recreation and occupational sun exposure $(3,39)$, early life outdoor 
activity (38), and objective measures of lifetime skin damage using a reflectometer (39).

Using these data, we investigated whether women who lived in the North/low solar irradiance compared with the Southern/high solar irradiance areas have differing risks of breast cancer depending on the amount of time they reported spending outside. We found that the HRs for breast cancer, among women living in low compared with high solar irradiance areas, were $<1.0$ for women who reported spending at least 30 minutes outside and $>1.0$ if they spent $<30$ minutes outside. This suggests that sunlight exposure may be protective against breast cancer among women living in extreme low compared with high solar irradiance areas. This may indicate that a minimal threshold of vitamin D exposure is required to prevent breast cancer. Although, this minimal amount is likely to vary among people by such factors influencing the ability of their skin to synthesize this vitamin such as age and skin pigmentation.

We also investigated if the observed protective effect of reported time spent outside, and breast cancer risk was modified by region of residence or solar irradiance. A previous study (15) found a protective effect of sun exposure on breast cancer risk among women residing in high solar irradiance areas but not medium or low solar irradiance areas. Differently, we observed that risk of breast cancer was increased among women who reported spending less compared with more time outside, regardless of region of residence or solar irradiance. These data were not always statistically significant.

Our study had a number of limitations. We were unable to investigate associations in premenopausal women, as WHIOS is a study of postmenopausal women. We did not have individual addresses of residence for participants and had to assume that they lived within the same latitude and solar irradiance area as their clinic center for the majority of WHIOS follow-up. Region of residence at earlier life periods were based on state of residence. We did not know where within the state a person had lived. We may have misclassified region of residence and this could have biased our results toward the null.

Additionally, we only had questions pertaining to average reported time spent outside, not specific questions about sunlight exposure, and these data were not available on all 71,662 women. We also had to make the

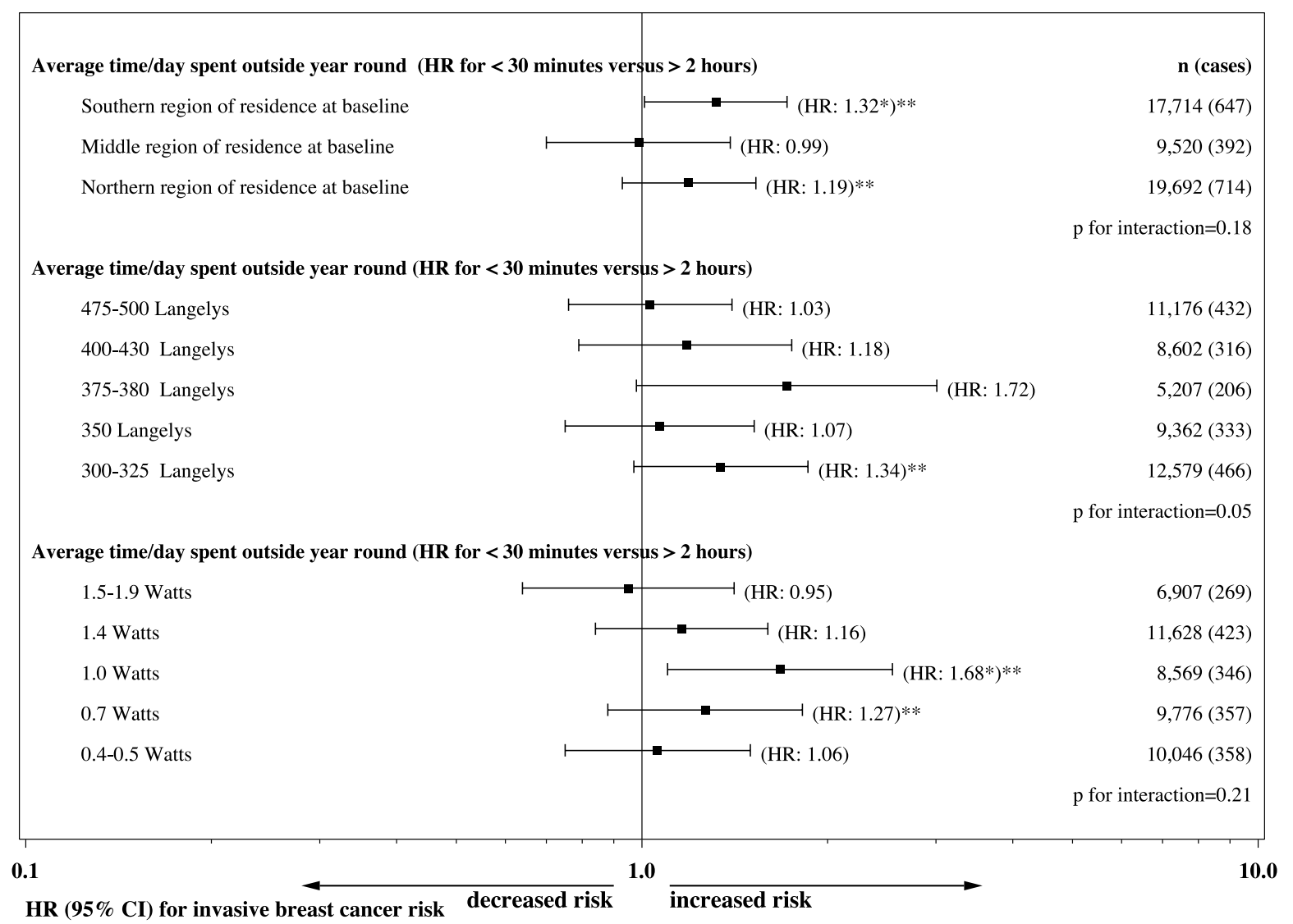

Figure 4. Adjusted (adjusted for age, race/ethnicity, education, weight, family history of breast cancer, age at menarche, age at menopause, parity, age at first birth, hormone therapy duration of use, alcohol intake, and recreational physical activity) HRs and 95\% CIs for incident breast cancer by average time per day spent outside year round stratified by region of residence at baseline and solar irradiance: the WHIOS. *, 95\% CI does not include 1.0. ${ }^{* *}, P_{\text {trend }}<0.05$; A test for trend was conducted using continuous variables for region of residence at baseline, Langleys, and Watts; A test for trend was conducted for average time per day spent outside year round using ordinal variables assigned to $<30,30 \mathrm{~min}$ to $2 \mathrm{~h}$, and $>2 \mathrm{~h}$. 
assumption that reported average time spent outside per day at year 4 follow-up was equal to baseline exposure. Investigation as to a more precise estimate of the amount of time needed to spend outside by location of residence and skin pigmentation was limited by the crude categories available on time spent outside. Future studies of breast cancer and sun exposure will need to address this in greater detail.

Additionally, WHIOS was composed of volunteers with somewhat greater than average educational attainment whose health-related behaviors may not generalize to the U.S. population. At the same time, this may have provided control for potential confounding due to education and SES. In this study, a number of statistical comparisons were made. Statistically significant results may be due to chance alone. However, a number of exposures were highly correlated (e.g., region of residence and solar irradiance), which lessens the problem of multiplicity. We also had no measures of serum D levels to determine how well the measures of geographic residence correlated to actual levels in these women.

The strength of our study was its large size and prospective design, which allowed us to investigate incident breast cancer data. We also were able to adjust for a great number of individually assessed breast cancer risk factors. Our regions of residence at baseline included 40 centers across the United States, incorporating 22 states, and we were also able to investigate associations by tumor characteristics, and other factors such as race/ ethnicity.

In summary, we did not observe consistent evidence that region of residence or regional solar irradiance is related to risk of incident invasive breast cancer. However, further analyses did suggest a protective effect from greater reported time spent outside. It is possible that region of residence or regionally defined solar irradiance are not good proxy measures of vitamin D status, and that measures of individual level behaviors related to sun exposure may provide better proxy measures for vitamin $D$ status than regional estimates of sun exposure. At the same time, our results may suggest that vitamin $\mathrm{D}$ is not related to risk of breast cancer. More research needs to be conducted to better understand how well region of residence and regional solar irradiance correlate to individually assessed vitamin D status and sunlight exposure. Prospective studies should continue to examine associations between breast cancer risk and individually assessed 25(OH)D and sunlight exposure status. At the same time, more prospective studies should examine the behaviors associated with individual level exposure to sun to better describe the associations between breast cancer risk and vitamin D status and sunlight exposure. As well, these behaviors need to be examined in the context of the lives of diverse racial and ethnic groups.

\section{Disclosure of Potential Conflicts of Interest}

Dr. A.M. Lopez: Commercial Research Grants with Novartis and Bayer; Honoraria from Speakers Bureau for AstraZeneca. Dr. Robert Langer has been an expert witness for Wyeth in litigation regarding the relationship between CEE plus MPA and breast cancer. The other authors disclosed no potential conflicts of interest.

\section{Acknowledgments}

The costs of publication of this article were defrayed in part by the payment of page charges. This article must therefore be hereby marked advertisement in accordance with 18 U.S.C. Section 1734 solely to indicate this fact.

\section{References}

1. Blot WJ, Fraumeni JF, Jr., Stone BJ. Geographic patterns of breast cancer in the United States. J Natl Cancer Inst 1977;59:1407-11.

2. Sturgeon SR, Schairer C, Gail M, McAdams M, Brinton LA, Hoover RN. Geographic variation in mortality from breast cancer among white women in the United States. J Natl Cancer Inst 1995; $87: 1846-53$

3. Freedman DM, Dosemeci M, McGlynn K. Sunlight and mortality from breast, ovarian, colon, prostate, and non-melanoma skin cancer: a composite death certificate based case-control study. Occup Environ Med 2002;59:257-62.

4. Garland FC, Garland CF, Gorham ED, Young JF. Geographic variation in breast cancer mortality in the United States: a hypothesis involving exposure to solar radiation. Prev Med 1990;19:614-22.

5. Grant WB, Garland CF. The association of solar ultraviolet B (UVB) with reducing risk of cancer: multifactorial ecologic analysis of geographic variation in age-adjusted cancer mortality rates. Anticancer Res 2006;26:2687-99.

6. Boscoe FP, Schymura MJ. Solar ultraviolet-B exposure and cancer incidence and mortality in the United States, 1993-2002. BMC Cancer 2006;6:264

7. Facchini U, Camnasio M, Cantaboni A, Decarli A, La Vecchia C. Geographical variation of cancer mortality in Italy. Int J Epidemiol 1985;14:538-48.

8. Gorham ED, Garland FC, Garland CF. Sunlight and breast cancer incidence in the USSR. Int J Epidemiol 1990;19:820-4.

9. Holick MF. Sunlight and vitamin D for bone health and prevention of autoimmune diseases, cancers, and cardiovascular disease. Am J Clin Nutr 2004;80:1678-88S.

10. Colston K, Colston MJ, Feldman D. 1,25-dihydroxyvitamin D3 and malignant melanoma: the presence of receptors and inhibition of cell growth in culture. Endocrinology 1981;108:1083-6.

11. Haussler CA, Marion SL, Pike JW, Haussler MR. 1,25-Dihydroxyvitamin D3 inhibits the clonogenic growth of transformed cells via its receptor. Biochem Biophys Res Commun 1986;139:136-43.

12. Cui $Y$, Rohan TE. Vitamin d, calcium, and breast cancer risk: a review. Cancer Epidemiol Biomarkers Prev 2006;15:1427-37.

13. Welsh J. Vitamin D and breast cancer: insights from animal models. Am J Clin Nutr 2004;80:1721-4S.

14. Laden F, Spiegelman D, Neas LM, et al. Geographic variation in breast cancer incidence rates in a cohort of U.S. women. J Natl Cancer Inst 1997;89:1373-8.

15. John EM, Schwartz GG, Dreon DM, Koo J. Vitamin D and breast cancer risk: the NHANES I Epidemiologic follow-up study, 19711975 to 1992. National Health and Nutrition Examination Survey. Cancer Epidemiol Biomarkers Prev 1999;8:399-406

16. Tarone RE, Chu KC, Gaudette LA. Birth cohort and calendar period trends in breast cancer mortality in the United States and Canada. J Natl Cancer Inst 1997;89:251-6.

17. Grant WB. An ecologic study of dietary and solar ultraviolet-B links to breast carcinoma mortality rates. Cancer 2002;94:272-81.

18. Anderson GL, Manson J, Wallace R, et al. Implementation of the Women's Health Initiative study design. Ann Epidemiol 2003; 13:S5-17.

19. Hays J, Hunt JR, Hubbell FA, et al. The Women's Health Initiative recruitment methods and results. Ann Epidemiol 2003;13:S18 -77.

20. Langer RD, White E, Lewis CE, Kotchen JM, Hendrix SL, Trevisan M. The Women's Health Initiative Observational Study: baseline characteristics of participants and reliability of baseline measures. Ann Epidemiol 2003;13:S107-21.

21. Curb JD, McTiernan A, Heckbert SR, et al. Outcomes ascertainment and adjudication methods in the Women's Health Initiative. Ann Epidemiol 2003;13:S122-8.

22. The SEER Program Code Manual, June 1992, NIH publication No. 92-1999, Cancer Statistics Branch, Surveillance Program, Division of Cancer Prevention and Control, National Cancer Institute, United States Department of Health and Human Services, Public Health Service, NIH, Washington, DC.

23. Block G. Health habits and history questionnaire: diet history and other risk factors. Personal Computer System Packet. Bethesda (MD): National Cancer Institute; 1989. 
24. Block G, Hartman AM, Dresser CM, Carroll MD, Gannon J, Gardner L. A data-based approach to diet questionnaire design and testing. Am J Epidemiol 1986;124:453-69.

25. Mares-Perlman JA, Klein BE, Klein R, Ritter LL, Fisher MR, Freudenheim JL. A diet history questionnaire ranks nutrient intakes in middle-aged and older men and women similarly to multiple food records. J Nutr 1993;123:489-501.

26. Subar AF, Thompson FE, Kipnis $\mathrm{V}$, et al. Comparative validation of the Block, Willett, and National Cancer Institute food frequency questionnaires: the Eating at America's Table Study. Am J Epidemiol 2001;154:1089-99.

27. Patterson RE, Kristal AR, Levy L, McLerran D, White E. Validity of methods used to assess vitamin and mineral supplement use. Am J Epidemiol 1998;148:643-9.

28. Patterson RE, Levy L, Tinker LF, Kristal AR. Evaluation of a simplified vitamin supplement inventory developed for the Women's Health Initiative. Public Health Nutr 1999;2:273-6.

29. No. 86-5 Cobb DA, United States Coordinates, 1986, (4-corner latitude/longitude for each state-degrees and minutes)" Coordinates: Online Journal of the Map and Geography Round Table, American Library Association, http://www.ala.org/ala/magert/publicationsab/usa.htm (accessed January 11, 2007).

30. Garland CF, Garland FC, Gorham ED, et al. The role of vitamin D in cancer prevention. Am J Public Health 2006;96: $252-61$.

31. Holick MF. Vitamin D deficiency. N Engl J Med 2007;357:266-81.

32. Garland CF, Garland FC. Do sunlight and vitamin D reduce the likelihood of colon cancer? Int J Epidemiol 1980;9:227-31.

33. Lubin D, Jensen EH, Gies HP. Global surface ultraviolet radiation climatology from TOMS and ERBE data. J Geophys Res 1998;103: 26061-91.

34. Cox DR. Regression models and life tables. J R Stat Soc [B] 1972;34: $187-220$.

35. SAS Institute Inc. SAS/STAT 9.1 User's Guide. Cary (NC): SAS Institute Inc.; 2004.

36. Grant WB. Epidemiology of disease risks in relation to vitamin D insufficiency. Prog Biophys Mol Biol 2006;92:65-79.

37. John EM, Schwartz GG, Koo J, Wang W, Ingles SA. Sun exposure, vitamin D receptor gene polymorphisms, and breast cancer risk in a multiethnic population. Am J Epidemiol 2007;166:1409-19.

38. Knight JA, Lesosky M, Barnett H, Raboud JM, Vieth R. Vitamin D and reduced risk of breast cancer: a population-based case-control study. Cancer Epidemiol Biomarkers Prev 2007;16:422-9.

39. John EM, Koo J, Schwartz GG. Sun exposure and prostate cancer risk: evidence for a protective effect of early-life exposure. Cancer Epidemiol Biomarkers Prev 2007;16:1283-6. 